\title{
Evaluation of Mint Mutants, Hybrids, and Fertile Clones for Resistance to Verticillium dahliae
}

Dennis A. Johnson, Professor, and Tom F. Cummings, Research Technician, Department of Plant Pathology, Washington State University, Pullman 99164-6430

\begin{abstract}
Johnson, D. A., and Cummings, T. F. 2000. Evaluation of mint mutants, hybrids, and fertile clones for resistance to Verticillium dahliae. Plant Dis. 84:235-238.

Peppermint and spearmint clones derived from cobalt 60 gamma irradiation and peppermint seed fertile clones and hybrids were evaluated for resistance to Verticillium dahliae in inoculation tests in the greenhouse. Mutant and fertile clones and hybrids varied significantly for wilt resistance. One peppermint mutant clone, three peppermint hybrids, and four peppermint fertile clones had low but varying wilt-severity values. Native spearmint and mutant lines derived from native spearmint had high levels of resistance. The wilt-severity scale used to assess disease levels was correlated with the number of CFU of V. dahliae from inoculated stems.
\end{abstract}

Three mint species, peppermint (Mentha $\times$ piperita L.), Scotch spearmint $(M . \times$ gracilis, Sole [M. cardiaca Baker]), and native spearmint (M. spicata L.), are commercially grown for their essential oils in the United States. The major production areas are the states of Washington, Oregon, Idaho, Montana, Wisconsin, Michigan, and Indiana.

Verticillium wilt, caused by Verticillium dahliae Kleb., is a limiting disease of peppermint and Scotch spearmint in all areas of production. Native spearmint is the most resistant and is not as severely damaged as the other two mint species; however, its oil has more limited commercial use (9). Stubble flaming and limited tillage (12), soil fumigation (8), crop rotation (6), and deep plowing (5) are only partially or temporarily effective in managing Verticillium wilt. Wilt-resistant cultivars coupled with disease-management practices that limit inoculum build up offer potential for managing the disease. Commercial mints are sterile (13), which precludes conventional breeding practices (1). However, progress has been achieved in developing wilt-resistant cultivars through induced mutation from vegetatively propagated peppermint $(13-15,17)$.

The Mint Industry Research Council (MIRC), a national organization of mint

Corresponding author: D. A. Johnson

E-mail: djohnsn@wsu.edu

PPNS No. 0289, Department of Plant Pathology, College of Agriculture and Home Economics Research Center, Project No. 0678, Washington State University, Pullman 99164-6430.

Accepted for publication 10 November 1999.

Publication no. D-2000-0110-03R

(C) 2000 The American Phytopathological Society growers, buyers, and manufacturers, sponsored an induced mutation breeding program directed by D. D. Roberts (Plant Technologies, Inc., Albany, OR) to develop wilt-resistant mint cultivars. In 1994, 81 mint lines that had low wilt-severity ratings and vigorous growth in field plots in Albany were sent to Pullman, Washington for maintenance and further wilt evaluations. The purpose of this study was to evaluate the MIRC mint selections for resistance to $V$. dahliae using inoculation tests in the greenhouse. The wilt-severity scale used to assess disease levels was correlated with the number of CFU of $V$. dahliae recovered from inoculated stems.

\section{MATERIALS AND METHODS}

A total of 81 mint clones were received from D. D. Roberts in September 1994. Included were 23 peppermint mutant lines, 26 peppermint hybrids, 21 peppermint seedlings and fertile lines, 5 Scotch spearmint mutant lines, and 6 native spearmint mutant lines. Peppermint, Scotch spearmint, and native spearmint mutants were derived from gamma-irradiated rhizomes with cobalt 60 at 8,000 to 20,0000 radiation absorbed dosage units in 1983 to 1984 and 1990 to 1991, using procedures previously described $(9,13)$. Over 105,000 rhizome cuttings were originally irradiated. Surviving plants were evaluated in the field near Albany, Oregon for growth habit and resistance to $V$. dahliae. The peppermint-seed fertile and hybrid clones were developed by D. D. Roberts from polyploid clones originally produced by M. J. Murray (A.M. Todd Co., Kalamazoo, MI.)

The mint selections and six commercial cultivars to be used as standards were maintained in pots $(15 \mathrm{~cm}$ in diameter) in a standard potting mix $(3: 1: 1$, peat moss:pumice:sand). Standard species were native spearmint, Scotch spearmint, and peppermint cvs. Roberts Mitcham, Murray Mitcham, Todds Mitcham, and Black Mitcham. White flies, mites, and powdery mildew were managed with sanitation practices and pesticides. Plants were regularly fertilized, thinned, trimmed, and transferred to new pots.

Rooted cuttings of selections and cultivars were grown for approximately 6 weeks to establish well-developed root systems before inoculation. Potting soil was gently dislodged from roots of rooted cuttings, after which rooted cuttings were inoculated by submerging roots in a conidial suspension of $V$. dahliae for $3 \mathrm{~min}$ before transplanting. Inoculum of $V$. dahliae was increased as conidia in liquid potato broth in shake culture for 6 days at 21 to $23^{\circ} \mathrm{C}$. Conidia were strained through four layers of cheese cloth, concentration determined with a hemacytometer, and distilled water added to form a desired concentration of $1 \times 10^{6}$ conidia $/ \mathrm{ml}$.

Rooted cuttings of entries and standards were inoculated in 1996 to initially determine the most-resistant materials. In 1997 and 1998, separate sets of rooted cuttings of all lines that exhibited either low $(<3.0)$ or intermediate (3.0 to 3.5 ) wilt-severity values during the initial test and six cultivar standards were again inoculated and evaluated for resistance. Two tests were used because rooted cuttings of all selected entries did not develop sufficient root systems for inoculation during a single test. The number of lines inoculated was 25 in 1997 and 37 in 1998. In both tests, 22 of the same lines and the standard were inoculated. A second test was done in 1998 to further evaluate four lines that had low wilt-severity values and one line with a high value during the previous two tests in 1997 and 1998. Two standards, Scotch spearmint and peppermint cv. Black Mitcham, were used as inoculated controls. Non-inoculated controls were used in all tests.

Three different isolates of $V$. dahliae were used for inoculations: isolate $\mathrm{V}-2$ in vegetative compatibility group (VCG) 2 from Scotch spearmint collected in Yakima county, Washington; isolate V-109 (VCG2) from cv. Black Mitcham peppermint collected in Grant County, Washington; and isolate V-605 (VCG-4A) from potato collected in Benton County, Washington. The two VCG-2 isolates were highly aggressive and more aggressive than the VCG-4A isolate on mint in previous stud- 
ies (4). Isolate $\mathrm{V}-2$ of $V$. dahliae was used in 1995 to 1997 , isolates V-2 and V-605 in the first test in 1998, and V-109 in a second test in 1998 (Table 1).

Entries in all tests were arranged in randomized complete blocks with five to eight replicates (1 cutting/repetition; Table 1). After inoculation, plants were placed in a greenhouse at temperatures ranging from 20 to $25^{\circ} \mathrm{C}$ during the day and 16 to $19^{\circ} \mathrm{C}$ at night. Natural light supplemented with sodium lamps (approximately $210 \mu \mathrm{mol} \mathrm{m} \mathrm{m}^{-2}$ $\mathrm{s}^{-1}$ photosynthetic active radiation) provided a photoperiod of at least $15 \mathrm{~h}$.

Verticillium wilt symptoms were assessed 8 to 9 weeks after inoculation, when plants had begun to flower. After disease ratings were taken, stems were cut near the soil line and plants were allowed to regrow. Wilt severity was assessed again, 5 to 6 weeks later, on the regrowth. The following scale was used for wilt assess- ments: $0=$ no visible symptoms, $1=$ mild chlorosis of upper $1 / 10$ of the plant, $2=$ distinct chlorosis in upper $1 / 10$ of the plant, $3=$ asymmetric growth in leaves or stems, stunting (four-fifths height of non-affected stems) and chlorosis of upper one-fifth of plant, $4=$ severe stunting (three-fifths height of non-affected stems and two-fifths or more of the tissue chlorotic), and $5=$ severe stunting and two-fifths or more necrotic tissue.

Table 1. Wilt-severity values of mint lines inoculated with Verticillium dahliae in four tests in the greenhouse from 1996 to $1998^{a}$

\begin{tabular}{|c|c|c|c|c|c|c|c|}
\hline \multirow[b]{2}{*}{ Genotype } & \multirow{2}{*}{$\begin{array}{l}1996^{b} \\
\text { Mean }\end{array}$} & \multicolumn{2}{|c|}{$1997^{c}$} & \multicolumn{2}{|c|}{$1998^{d}$} & \multicolumn{2}{|c|}{$1998^{e}$} \\
\hline & & 1st growth & Regrowth & 1st growth & Regrowth & 1st growth & Regrowth \\
\hline \multicolumn{8}{|l|}{ Peppermint mutant } \\
\hline $\mathrm{T}-83-4$ & 2.8 & $\ldots$ & $\ldots$ & 3.4 & 3.5 & $\ldots$ & $\ldots$ \\
\hline M-91-7 & 3.5 & $\ldots$ & $\ldots$ & 3.3 & 3.5 & $\ldots$ & $\ldots$ \\
\hline M-90-11 & 3.0 & 2.5 & 2.8 & 2.2 & 2.0 & $\ldots$ & $\ldots$ \\
\hline M-91-10 & 3.0 & 2.3 & 3.3 & 3.4 & 3.5 & $\ldots$ & $\ldots$ \\
\hline M-83-14 & 3.3 & 3.3 & 3.4 & 3.2 & 4.0 & $\ldots$ & $\ldots$ \\
\hline B-83-8 & 3.2 & $\ldots$ & $\ldots$ & 3.3 & 3.3 & $\ldots$ & $\ldots$ \\
\hline B- $90-9$ & 3.0 & 3.8 & 4.8 & 4.3 & 4.5 & $\ldots$ & $\ldots$ \\
\hline M-84-20 & 3.1 & 2.8 & 3.6 & $\ldots$ & $\ldots$ & $\ldots$ & $\ldots$ \\
\hline B- $90-5$ & 3.0 & 3.5 & 4.3 & $\ldots$ & $\ldots$ & $\ldots$ & $\ldots$ \\
\hline \multicolumn{8}{|l|}{ Peppermint hybrid } \\
\hline 84-M0107-7 & 1.7 & $\ldots$ & $\ldots$ & 1.8 & 2.2 & 2.1 & 1.5 \\
\hline 89-14-M0112-9 & 2.4 & 3.2 & 3.3 & 3.0 & 3.6 & $\ldots$ & $\ldots$ \\
\hline 92(M0109xOP) & 2.8 & 4.8 & 4.8 & 4.8 & 5.0 & $\ldots$ & $\ldots$ \\
\hline $90(0959-2)-3$ & 2.5 & 1.2 & 2.2 & $\ldots$ & $\ldots$ & 2.1 & 2.4 \\
\hline 87-M0109-1 & 3.1 & 2.2 & 1.7 & 1.8 & 3.5 & 2.7 & 2.1 \\
\hline 86-M0105-1 & 2.7 & 3.3 & 3.3 & 3.1 & 3.8 & $\ldots$ & $\ldots$ \\
\hline 84-M0113-1 & 2.4 & 2.3 & 2.3 & 2.5 & 3.8 & 3.5 & 3.5 \\
\hline $89(0959 x 0957)-2$ & 2.7 & 4.7 & 4.7 & 4.1 & 4.9 & $\ldots$ & $\ldots$ \\
\hline 84-M0112-3 & 3.1 & 4.2 & 3.8 & 4.0 & 3.8 & $\ldots$ & $\ldots$ \\
\hline $89(0959-2)$ & 2.9 & $\ldots$ & $\ldots$ & 4.3 & 4.1 & 3.0 & 2.7 \\
\hline $90(0960-1)-2$ & 2.2 & 3.2 & 4.2 & 4.1 & 3.8 & $\ldots$ & $\ldots$ \\
\hline 92(B-37xM0110)-1 & 3.3 & 4.3 & 4.5 & 4.3 & 4.5 & $\ldots$ & $\ldots$ \\
\hline $92(\mathrm{~B}-26 \times \mathrm{M}-38)$ & 2.8 & 4.8 & 4.5 & 4.3 & 4.0 & $\ldots$ & $\ldots$ \\
\hline 88-M0110-1 & 3.0 & 4.5 & 4.5 & 4.5 & 4.8 & $\ldots$ & $\ldots$ \\
\hline \multicolumn{8}{|l|}{ Peppermint seedling ${ }^{f}$} \\
\hline 93(85-M0102-1)-16 & 2.3 & 2.5 & 2.0 & 2.4 & 2.3 & $\ldots$ & $\ldots$ \\
\hline $93[85(0959 \times 0957)-1]-17$ & 2.2 & 4.2 & 4.3 & 3.6 & 3.6 & $\ldots$ & $\ldots$ \\
\hline 93(85-M0102-1)-9 & 3.4 & $\ldots$ & $\ldots$ & 2.7 & 3.4 & $\ldots$ & $\ldots$ \\
\hline $93[85(0959 \times 0957)-1]-1$ & 3.0 & $\ldots$ & $\ldots$ & 2.3 & 3.0 & $\ldots$ & $\ldots$ \\
\hline \multicolumn{8}{|l|}{ Fertile line (polyploid) } \\
\hline M0108 & 2.7 & $\ldots$ & $\ldots$ & 3.0 & 2.9 & $\ldots$ & $\ldots$ \\
\hline M-38 & 2.8 & $\ldots$ & $\ldots$ & 3.0 & 3.1 & $\ldots$ & $\ldots$ \\
\hline B-37 & 3.1 & 3.3 & 3.2 & 3.0 & 3.7 & $\ldots$ & $\ldots$ \\
\hline M-27 & 3.5 & $\ldots$ & $\ldots$ & 4.2 & 4.7 & $\ldots$ & $\ldots$ \\
\hline M-26 & 3.5 & 2.3 & 2.2 & 1.7 & 1.7 & $\ldots$ & $\ldots$ \\
\hline \multicolumn{8}{|l|}{ Scotch mutant } \\
\hline S-90-6 & 2.7 & 2.4 & 1.8 & 3.0 & 3.7 & $\ldots$ & $\ldots$ \\
\hline S-90-9 & 2.8 & 2.5 & 3.8 & 3.3 & 3.1 & $\ldots$ & $\ldots$ \\
\hline \multicolumn{8}{|l|}{ Native mutant } \\
\hline N-87-1 & 1.0 & $\ldots$ & $\ldots$ & 1.8 & 1.4 & $\ldots$ & $\ldots$ \\
\hline $\mathrm{N}-83-22$ & 1.4 & 1.5 & 1.3 & 1.3 & 1.6 & $\ldots$ & $\ldots$ \\
\hline N-83-6 & 2.1 & $\ldots$ & $\ldots$ & 1.3 & $\ldots$ & $\ldots$ & $\ldots$ \\
\hline $\mathrm{N}-83-23$ & 1.8 & $\ldots$ & $\ldots$ & 1.7 & 1.7 & $\ldots$ & $\ldots$ \\
\hline $\mathrm{N}-83-5$ & 1.5 & $\ldots$ & $\ldots$ & 1.4 & 1.5 & $\ldots$ & $\ldots$ \\
\hline N-83-21 & 1.8 & $\ldots$ & $\ldots$ & 1.6 & 1.3 & $\ldots$ & $\ldots$ \\
\hline \multicolumn{8}{|l|}{ Standards } \\
\hline Native spearmint & 2.0 & 1.2 & 1.0 & 1.4 & 1.3 & $\ldots$ & $\ldots$ \\
\hline Scotch spearmint & 2.7 & 3.2 & 3.0 & 3.0 & 3.6 & 3.6 & 3.7 \\
\hline Roberts Mitcham & 2.7 & 3.3 & 4.0 & 3.5 & 4.5 & $\ldots$ & $\ldots$ \\
\hline Murray Mitcham & 3.0 & 3.3 & 4.5 & 3.1 & 3.5 & $\ldots$ & $\ldots$ \\
\hline Todds Mitcham & 4.2 & 3.3 & 4.2 & 3.5 & 3.9 & $\ldots$ & $\ldots$ \\
\hline Black Mitcham & 4.4 & 4.3 & 4.7 & 3.8 & 4.1 & 4.3 & 4.4 \\
\hline Least significant difference & 0.9 & 0.6 & 0.9 & 0.8 & 1.0 & 0.8 & 1.0 \\
\hline
\end{tabular}

a Wilt severity value ranged from 0 (no disease symptoms) to 5 ( $40 \%$ or more necrotic tissue).

${ }^{\mathrm{b}}$ Values are means from five replicates, inoculated with isolate V-2 (VCG-2).

${ }^{c}$ Values are means of six replicates, inoculated with isolate V-2 (VCG-2).

${ }^{d}$ Values are means of eight replicates, inoculated separately with isolates V-2 (VCG-2) and V-605 (VCG-4A).

e Values are means of eight replicates, inoculated with isolate V-109 (VCG-2).

${ }^{\mathrm{f}}$ Lines from first recurrent selection. 
Correlation of disease severity rating with CFU of $\boldsymbol{V}$. dahliae in inoculated stems. In 1995, each of four replicates of 24 lines with mean disease-severity ratings ranging from 0 to 4 were selected. Approximately 16 weeks after inoculation, three stem sections $(2 \mathrm{~cm}$ each) were cut from $1 \mathrm{~cm}$ above the soil line, from the center of the stem, and three-fourths of the distance from the base. They were washed in running tap water, disinfested for $3 \mathrm{~min}$ in $0.5 \% \mathrm{NaOCL}$, and placed on moistened filter paper in petri dishes. About $0.1 \mathrm{ml}$ of a $0.015 \%$ solution of Gramoxone $(20.4 \%$ paraquat), a desiccant herbicide, was then applied to each stem section (16). Stem pieces were incubated at $23^{\circ} \mathrm{C}$ and observed for 2 to 3 weeks for growth of $V$. dahliae. The proportion of infected stem pieces per clone was determined. In 1997, about 16 weeks after inoculation, 43 mint lines and cultivars with disease-severity rating ranging from 0 to 4 were selected. A stem section, $3 \mathrm{~cm}$ in length, was cut $1 \mathrm{~cm}$ above the soil line from a stem of each plant, washed, disinfested in $0.5 \% \mathrm{NaOCl}$ for $3 \mathrm{~min}$, placed in a polyethylene bag, and then smashed with a vise. Distilled water $(1 \mathrm{ml})$ was added to the plant sap and $0.5 \mathrm{ml}$ of the resultant suspension was evenly spread on NPX agar medium $(3,12)$, and incubated for two weeks. Colonies of $V$. dahliae were counted.

Disease-severity data of inoculated clones and cultivars were analyzed using analysis of variance. Least significant difference was used to compare lines with standards and a single degree of freedom contrast was used to compare pathogenicity of $V$. dahliae isolates V-2 (mint) and V605 (potato). The proportion of infected stem pieces per clone was used with 1996 data and number of CFU per centimeter of stem was used with 1997 data. Data were analyzed by analysis of variance using the GLM procedure of SAS (version 6.12; SAS Institute, Inc., Cary, NC). The correlation of disease severity with CFU of $V$. dahliae in inoculated stems was tested with Spearman's rank correlation.

\section{RESULTS}

Symptoms of Verticillium wilt developed on all inoculated mint lines and cultivars and $V$. dahliae was consistently reisolated from inoculated plants. Disease symptoms did not develop on non-inoculated controls. Significant differences $(P<$ 0.05 ) for wilt severity were found among the mint lines and cultivars tested (Table 1). Table 1 contains values for six standards and the 40 lines selected from the original 81 lines.

Cv. Black Mitcham peppermint consistently had wilt severity ratings of 3.7 or higher. Mean ratings for Scotch spearmint ranged from 2.7 to 3.6. Native spearmint and the native mutants had lower wilt-severity ratings than the other lines (Table 1). The peppermint mutant, M-90-11, the pep- permint hybrids, 87-M0109-1, 84-M01077, and 90(0959-2)3, and the fertile parent M-26 had low wilt-severity ratings (Table $1)$.

Wilt-severity ratings were significantly higher $(P<0.01)$ when lines and cultivars were inoculated with $V$. dahliae isolate V-2 (VCG-2) than with V-605 (VCG-4A). Significant interactions between isolates and mint lines were not found and values for the two isolates were combined (Table 1). Mean severity values on the first and regrowth, respectively, were 3.2 and 3.4 for isolate V-2 and 2.7 and 3.1 for V-605. Wilt-severity values for standards and lines inoculated with isolate V-109 (VCG-2) in 1998 were similar to those obtained for the same entries when inoculated with isolate V-2 (VCG-2) in tests during 1996 to 1997.

Disease-severity ratings were significantly correlated with CFU of the pathogen in inoculated stems. Spearman's rank correlation coefficient was $0.82(P=0.0001)$ with 1996 data and $0.86(P=0.0001)$ with 1997 data.

\section{DISCUSSION}

Variation for resistance to Verticillium wilt was found among irradiated mint clones, hybrids, and fertile lines. No line was completely resistant to $V$. dahliae in this or previous studies $(9,15)$. In an earlier study (1), a range of levels of wilt resistance was identified in various natural mint species, with $M . \times$ piperita being very susceptible and $M$. crispa possessing a high level of resistance. Native spearmint exhibited a high level of resistance in this study, and resistance in native spearmint has been stable when inoculated with various isolates of $V$. dahliae (4). However, native spearmint will develop wilt symptoms when planted in soils with high levels of $V$. dahliae or propagated from infected planting stock (D. A. Johnson, unpublished data).

Both VCG-2 isolates (V-2 and V-109) used in this study were highly pathogenic on mint, as indicated by the high wilt-severity values on cv. Black Mitcham peppermint. The isolate of $V$. dahliae from potato (VCG-4A) was less pathogenic on mint than isolate V-2 (VCG-2) from mint. Differences in pathogenicity among $V$. dahliae isolates from various hosts to mint has been reported previously $(4,7)$.

The wilt-severity scale used in this study adequately distinguished differences in levels of wilt resistance and was positively correlated with the level of $V$. dahliae CFU in inoculated stems. Similarly, more propagules of $V$. dahliae were isolated from the susceptible species, $M . \times$ piperita, than from stems of the resistant species, $M$. crispa (2). A similar situation was found in potato, where more propagules were recovered from stems of susceptible than from resistant cultivars (10).

Mutation breeding has been effective in developing mint cultivars resistant to $V$. dahliae $(14,17)$. Resistant lines were identified in this study that should be further evaluated in the field for resistance to other diseases and agronomic traits, including yield, oil quality, and winter hardiness. Selected lines could also be used in breeding programs using traditional (if seedfertile) and molecular techniques to produce more resistant cultivars. Previously, it has been extremely difficult to combine resistance to $V$. dahliae and satisfactory oil quality (13). Expression of wilt resistance in mint is affected by soil temperature (1) and inoculum concentration (11). An intermediate level of resistance may be adequate for commercial production (1). Integrating resistance with cultural practices that promote Verticillium spp.-free planting stock, clean ground, long rotations with specific crop sequences and weed management, and a limited number of years that fields are in production over a given number of growing seasons would make wilt resistance more effective.

\section{ACKNOWLEDGMENTS}

We thank R. Green and T. Davis for critically reviewing this manuscript.

\section{LITERATURE CITED}

1. Berry, S. Z., and Thomas, C. A. 1961. Influence of soil temperature, isolates, and method of inoculation on resistance of mint to Verticillium wilt. Phytopathology 51:169-174.

2. Brandt, W. H., Lacy, M. L., and Horner, C. E. 1984. Distribution of Verticillium in stems of resistant and susceptible species of mint. Phytopathology 74:587-591.

3. Butterfield, E. J., and DeVay, J. E. 1997. Reassessment of soil assays for Verticillium dahliae. Phytopathology 67:1073-1078.

4. Douhan, L. I., and Johnson, D. A. 1998. Vegetative compatibility and pathogenicity of Verticillium dahliae isolates from spearmint and peppermint. Phytopathology 88:S23.

5. Green, R. J., Jr., 1958. "Deep plowing" for controlling Verticillium wilt of mint in muck soils. Phytopathology 48:575-577.

6. Green, R. J., Jr. 1967. Control of Verticillium wilt of peppermint by crop rotation sequences. Plant Dis. Rep. 51:449-453.

7. Horner, C. E. 1954. Pathogenicity of Verticillium isolates to peppermint. Phytopathology 44:239-242.

8. Horner, C. E., and Dooley, H. L. 1966. Control of Verticillium wilt of peppermint by soil fumigation. Plant Dis. Rep. 50:97-100.

9. Horner, C. E., and Melouk, H. A. 1977. Screening, selection, and evaluation of irradiation-induced mutants of spearmint for resistance to Verticillium wilt. Int. Atomic Energy Agency-SM:214/20:253-262.

10. Hoyos, G. P., Zambino, P. J., and Anderson, N. A. 1991. An assay to quantify vascular colonization of potato by Verticillium dahliae. Am. Potato J. 68:727-742.

11. Lacy, M. L., and Horner, C. E. 1965. Verticillium wilt of mint: Interactions of inoculum density and host resistance. Phytopathology 55:1176-1178.

12. McIntyre, J. L., and Horner, C. E. 1973. Inactivation of Verticillium dahliae in peppermint stems by propane gas flaming. Phytopathology 63:172-175.

13. Murray, M. J. 1971. Additional observations on mutation breeding to obtain Verticilliumresistance strains of peppermint. Mutation Breeding for Disease Resistance. Int. Atomic Energy Agency. pp. 171-195. 
14. Murray, M. J., and Todd, W. A. 1972. Registration of Todd's Mitcham peppermint. Crop Sci. 12:128.

15. Murray, M. J., and Todd, W. A. 1975. Role of mutation breeding in genetic control of plant diseases. Pages 172-176 in: Biology and Control of Soil-Borne Plant Pathogens. G. W. Bruehl, ed. American Phytopathological Society, St. Paul, MN

16. Sinclair, J. B. 1991. Latent infection of soy- bean plants and seeds by fungi. Plant Dis. 75:220-224.

17. Todd, W. A., Green, R. J., Jr., and Horner, C. E. 1977. Registration of Murray Mitcham peppermint. Crop Sci. 17:188 